\title{
(2) \\ Códigos estéticos, expresiones plásticas y modos de representación en la cerámica del Formativo en Yutopián (Valle del Cajón, Noroeste argentino)
}

RMA

Arqueología

María Fabiana Bugliani

CONICET-Museo Etnográfico "Juan B. Ambrosetti", Facultad de Filosofía y LetrasUniversidad de Buenos Aires. E-mail: fbugliani@gmail.com

\begin{abstract}
Resumen
Las expresiones plásticas, como toda producción, son una labor surgida en un contexto cultural e históricamente dado y se encuentran sujetas a códigos estéticos, preferencias sociales y valoraciones propias de los espacios sociales en donde tales manifestaciones se produjeron, circularon y fueron consumidas. Estas expresiones son representaciones en tanto son objetivación de creencias, ideas y valores de un determinado grupo social y se presentan como un modo particular de manifestación que se encuentra social y culturalmente situado.

En el caso de los recipientes cerámicos, sabemos que los mismos han participado de numerosas acciones de la vida cotidiana en el pasado. En este artículo se analizan los recursos plásticos que fueron movilizados y puestos 'en acción' en las vasijas de Yutopián, una aldea formativa del valle del Cajón, Noroeste argentino, del primer milenio de la era Cristiana. El estudio detallado de diferentes contextos en dos núcleos habitacionales nos mostró un despliegue diferencial de los modos de representación elegidos, los recursos expresivos utilizados y los tipos de recipientes empleados, permitiendo avanzar algunas ideas sobre el rol de los objetos y expresiones plásticas en diferentes situaciones de la vida social.
\end{abstract}

Palabras Clave: vasijas cerámicas; expresiones plásticas; códigos estéticos; consumo; Noroeste argentino.

Aesthetic codes, artistic expressions and modes of representation in the formative pottery from Yutopián (Cajón Valley, Northwest Argentina)

\begin{abstract}
Plastic expressions, as any other production, are creations that arise within a certain historic and cultural context, thus being subject to aesthetic codes, social preferences, and valuations specific of the social spaces in which such manifestations were produced, circulated and consumed. These expressions are representations as far as they are objectivations of beliefs, ideas and values of particular social groups, presenting themselves as a specific mode of representation that is socially and culturally situated.

In the case of ceramic vessels, we know that these have participated of a number of actions in the everyday life of the past. This article analyses the plastic resources which were mobilized and put 'into action' in the vessels of Yutopián, a Formative village of the Cajón valley, Northwestern Argentina, dated to the first millennium of the Christian era. A detailed study of the different contexts of two household compounds evidenced a differential display of the representational modes that were chosen, the expressive resources that were utilized and the types of recipients used, thus allowing to advance some ideas regarding the role of objects and plastic expressions in different situations of the social life.
\end{abstract}

Keywords: ceramic vessels; plastic expressions; aesthetics codes; consumption; Northwestern Argentina.

Desde diversas perspectivas se ha proclamado la necesidad de analizar y explicar las expresiones plásticas "no occidentales" entendiendo que las mismas son producto de situaciones sociales, históricas, simbólicas, políticas y económicas particulares (e.g. Shanks y Tilley 1987; Delgado 1988; Shelton 1992; Dutton 1998; Gell 1998).

Contrariamente, cuando se realizaron estudios de estas manifestaciones plásticas desde la óptica de la Historia del Arte occidental, se aplicaron parámetros estéticos occidentales con la consecuente descontextualización de las obras. De esta forma, en reiteradas oportunidades esculturas, vasijas o murales pasaron a considerarse objetos de valor estético 'universal', perdiendo al mismo tiempo, su carácter simbólico original y su relación con el contexto en el cual fueron creados.

Desde una perspectiva que busca desarrollar una teoría antropológica del arte visual, Alfred Gell (1998: 3) planteó que antes que realizar una evaluación apreciativa de los trabajos artísticos se debe focalizar en el contexto social 
de producción, circulación y consumo de los mismos. Estas obras circulan en diversos contextos y procesos sociales y son precisamente estos espacios, el ámbito donde adquieren sentido.

Las expresiones plásticas, como toda producción, son parte de una red de relaciones y están sujetas a códigos estéticos, preferencias sociales, principios y valoraciones, compartidos por quienes conformaron el entramado social en el cual estas manifestaciones estuvieron presentes. Es por ello que si queremos analizar estas expresiones, es necesario conocer las condiciones en las cuales estuvieron implicadas y las relaciones dentro de las cuales estuvieron entramadas.

En este sentido, Gell (1998) propuso estudiar los principios estéticos en el curso de la interacción social, evaluando los objetos y las representaciones plásticas en relación a su rol mediador en los procesos sociales. Al respecto, se considera que los objetos -y las expresiones plásticas portadas por lo mismos- poseen un tipo particular de agencia social. Esta agencia, ejercida por los objetos, como pueden ser, por ejemplo, los contenedores cerámicos utilizados en diferentes situaciones de la vida cotidiana, viene dada por una intención humana que se objetiva o manifiesta en una forma artefactual. El origen de la agencia tiene lugar en un entorno social y si bien los objetos no son agentes primarios que inician situaciones por si mismos, son objetivación de capacidad y acción, quedando plasmada la agencia en diferentes formas materiales.

Asimismo, Gosden (2001) advierte que los objetos son activos sólo en la manera que puede serlo un objeto, no pensando en ellos como personas. La acción de los objetos está dada por su capacidad para generar distintas sensaciones sobre la gente. Esta potencialidad se ve desarrollada en la interacción permanente que ocurre entre las percepciones humanas y el mundo material que nos rodea. Siguiendo a este autor, las cualidades estéticas están en relación con la capacidad de ciertos tipos de objetos de atraer la atención e impactar sensorialmente más que otros (Gosden 2001: 16). El valor que se les asigna a determinados objetos deriva en parte del impacto que los mismos provocan. Así se van creando valoraciones y sentidos que se ponen en juego en la continua interacción entre personas y cosas.

Siguiendo estas ideas, pensamos que las representaciones plásticas expresadas en las vasijas cerámicas, son activas en la medida en que las personas ponen en ellas creencias, ideas, esquemas perceptivos y sensoriales. Estos objetos 'actúan' en diferentes situaciones de acuerdo a los juicios y valoraciones de quienes participan en el entramado social y puede accederse a ellos a través del estudio de los contextos de los cuales forman parte.

Durante el primer milenio d.C. las sociedades aldeanas del valle del Cajón (Catamarca, Argentina), plasmaron sobre sus recipientes cerámicos una serie de representaciones que circularon por diferentes contextos y participaron de distintas actividades. Las investigaciones realizadas en este valle, durante más de una década en el sitio Yutopián (e.g. Gero y Scattolin 1994, 1999, 2002; Campo 1997; Scattolin y Gero 1999; Izeta 2007; Bugliani 2008) han permitido recuperar un registro muy completo que nos brinda una excelente oportunidad para estudiar los contenedores cerámicos y sus expresiones plásticas como parte de un contexto doméstico aldeano. Al encarar el estudio de estas vasijas, su iconografía y el contexto del cual fueron parte, surgen interrogantes acerca de qué expresiones plásticas se hallaban representadas en los diferentes espacios, cómo se movilizaron los principios estéticos en las expresiones plásticas de la cerámica y cómo actuaron en las diferentes situaciones domésticas, rituales, comunitarias, familiares, etc. Para abordar estas cuestiones analizaremos las expresiones plásticas en las vasijas atendiendo a los modos de representación elegidos, los recursos expresivos utilizados, la distribución y consumo de diferentes tipos de recipientes en espacios diversos y las relaciones sociales en las cuales se vieron implicadas.

\section{La aldea de Yutopián: objetos cerámicos, estilos, expresiones plásticas}

El sitio Yutopián está situado en el valle del Cajón, ubicado al occidente del valle de Santa María, en un punto intermedio antes de acceder al borde sur oriental de la Puna. Se emplaza en el sector central del valle, en la vertiente occidental del río Colorado, sobre una colina que se sobreeleva de una pendiente inclinada (Figura 1).

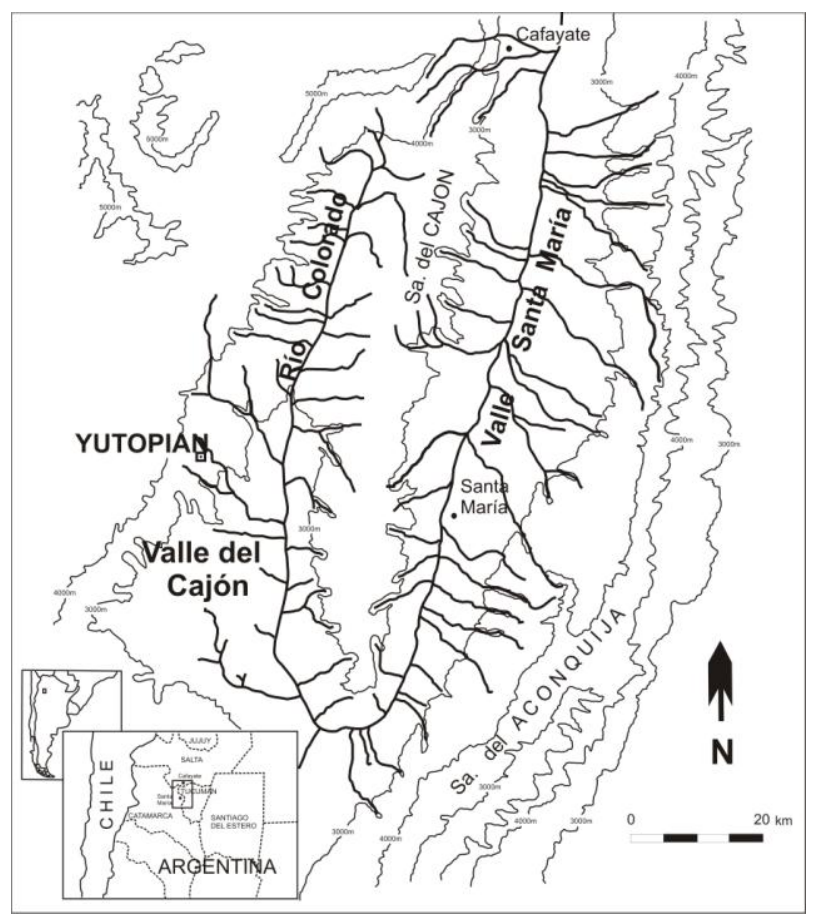

Figura 1. Localización de Yutopián, valle del Cajón. 


\begin{tabular}{|c|c|c|c|}
\hline \multirow{17}{*}{ 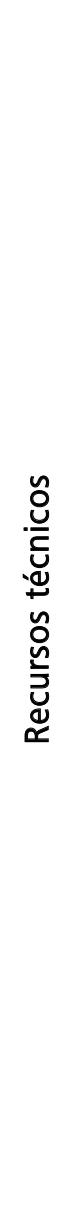 } & \multirow{6}{*}{$\begin{array}{l}\text { Incisión, } \\
\text { excisión, } \\
\text { grabado }\end{array}$} & $\ln 1$ & Sección en "V", realizada con un instrumento de punta aguzada. \\
\hline & & $\ln 2$ & Sección en "U", surco más ancho que profundo. \\
\hline & & $\ln 3$ & $\begin{array}{l}\text { Círculos de alrededor de } 5 \mathrm{~mm} \text { de diámetro, realizada con un con } \\
\text { instrumento cilíndrico. }\end{array}$ \\
\hline & & $\ln 4$ & $\begin{array}{l}\text { Corresponde a grabado, realizado con un instrumento de punta muy fina, } \\
\text { deja un surco muy delgado. }\end{array}$ \\
\hline & & $\ln 5$ & $\begin{array}{l}\text { Corresponde a grabado, realizado con un instrumento de punta múltiple, } \\
\text { una escobilla de pocas puntas muy delgadas. }\end{array}$ \\
\hline & & $\ln 6$ & $\begin{array}{l}\text { Corresponde a excisión, aparece combinada con elementos modelados } \\
\text { donde con un instrumento se ha producido un corte y se ha removido parte } \\
\text { del material. }\end{array}$ \\
\hline & \multirow[t]{9}{*}{ Pintura } & Pi1 & Blanco y negro sobre fondo rojo, líneas paralelas. \\
\hline & & Pi2 & $\begin{array}{l}\text { Rojo delimitado por una línea blanca sobre pasta beige, motivos } \\
\text { geométricos. }\end{array}$ \\
\hline & & Pi3 & Blanco sobre rojo, líneas. \\
\hline & & Pi4 & Marrón y blanco sobre rojo, diseños de líneas. \\
\hline & & Pi5 & Negro sobre pasta beige, líneas paralelas y zigs-zags. \\
\hline & & Pi6 & Negro, blanco y rojo sobre pasta beige, triángulos. \\
\hline & & $\mathrm{Pi7}$ & Blanco sobre pasta gris, círculos. \\
\hline & & Pi8 & Blanco, negro y rojo sobre pasta beige, círculos concéntricos. \\
\hline & & Pi9 & Blanco sobre rojo, elementos geométricos. \\
\hline & \multirow[t]{2}{*}{ Modelado } & M1 & Pequeños modelados realizados sobre el borde o labio de la vasija. \\
\hline & & M2 & $\begin{array}{l}\text { Modelados en el cuello y cuerpo de la pieza produciendo rasgos para } \\
\text { configurar diseños figurativos. }\end{array}$ \\
\hline
\end{tabular}

Tabla1. Recursos técnicos empleados en la elaboración de las expresiones plásticas de los recipientes cerámicos de Yutopián.

Yutopián comprende diferentes componentes, pero las ocupaciones correspondientes al Período Formativo -que son las que nos interesan en este trabajo- se concentran en el área norte del sitio, el cual no muestra reocupaciones correspondientes al Período de Desarrollos Regionales excepto en algunas zonas circunscriptas (Scattolin y Gero 1999). El área norte, denominada Sector III, presenta diversas estructuras en su mayoría circulares y subcirculares que se agrupan en pequeñas aglomeraciones de tamaño variable conformando una aldea cuya temporalidad abarcaría entre el 200 a.C y el 600 d.C (Scattolin y Gero 1999; Scattolin 2007). En este conjunto fueron excavadas dos unidades domésticas (Núcleos 1y 2), compuestas por cantidad variable de estructuras y con una configuración de patio semiabierto con habitaciones adosadas.

El material cerámico recuperado en los distintos recintos muestra un mayor consumo de cerámica Ordinaria, sin representaciones plásticas -excepto unos escasos fragmentos-, por sobre la cerámica del grupo Fino/ Intermedio ${ }^{1}$ en los cuales se presentan tratamientos de

\footnotetext{
${ }^{1}$ La distinción general en grupos Ordinario y Fino responde a la manera tradicional de realizar una primera discriminación del material cerámico de momentos formativos del NOA para lo cual se han tenido en cuenta criterios estilísticos, de forma, manufactura y decoración. En Yutopián hemos distinguido siete tipos cerámicos (Scattolin 1999, Bugliani 2008),
}

superficie pulidos, expresiones plásticas y un acabado general más cuidado. La relación entre fragmentos del grupo Fino/Intermedio y fragmentos del grupo Ordinario ${ }^{2}$ es de 0.22 es decir, un $82 \%$ corresponde a recipientes Ordinarios y $18 \%$ a vasijas de la serie Fina/Intermedia. A pesar de su escasez relativa, el material cerámico de esta última serie aparece representado en el sitio por una amplia variabilidad estilística y morfológica, por lo que resulta relevante analizar este conjunto. Entre los materiales cerámicos de Yutopián aparecen fragmentos Gris Inciso muy bien pulidos, otros grises con motivos asimilables a los presentes en los estilos 'Río Diablo' y 'Ciénaga', también material pintado en rojo con motivos en blanco y/o negro como en 'Condorhuasi' y algunas piezas de pastas intermedias con diseños antropomorfos modelados similares a ejemplares de 'Tafi-Candelaria' (Scattolin y Gero 1999).

Las representaciones en la cerámica que circuló y se consumió en Yutopián son el resultado de la utilización de

entre ellos, uno que denominamos Intermedio por presentar rasgos en grado intermedio entre los dos grupos mencionados y combinar características de ambos. A los fines de este artículo hemos incluido el tipo Intermedio en el grupo Fino, denominando al conjunto Fino/Intermedio.

${ }^{2}$ Se usó como índice la relación existente entre las frecuencias de ambos grupos: indicador servirng-to-cooking ratio de acuerdo a la propuesta de Welch y Scarry (1995). 


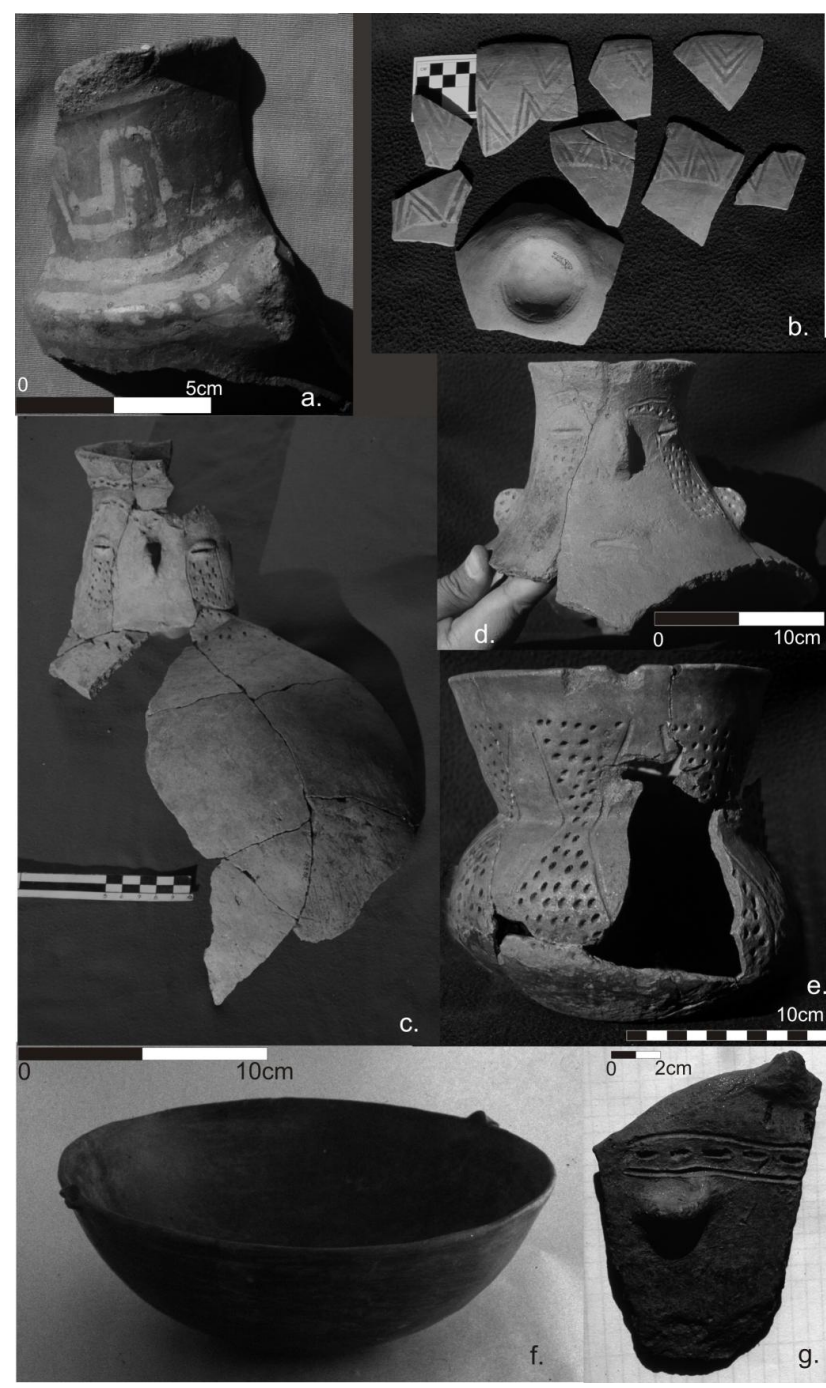

Figura 2. Vasijas cerámicas de Yutopián.

una serie de recursos técnicos, compositivos e iconográficos combinados de maneras particulares. Para confeccionar las representaciones se emplearon la pintura, la incisión, el modelado y el pastillaje (Tabla 1)

Dentro de la técnica de incisión se presentan diferentes variantes que podrían ser reflejo tanto de los instrumentos usados como del modo de ejecución. Se distinguen diferentes tipos de incisión de acuerdo a la sección del surco, la forma lineal o cilíndrica del inciso, el instrumento usado y el momento de su ejecución respecto del secado de la pieza. En la pintura se aprecian distinciones de acuerdo a los colores -aparecen el color rojo, blanco y en menor medida el negro-, las combinaciones entre ellos y el espesor de los trazos. Con la técnica de modelado y pastillaje se realizaron dos tipos de diseños. Por un lado, pequeños modelados, generalmente semicirculares, ubicados sobre el borde o labio de la vasija, a veces con puntos incisos o representando zoomorfos muy estilizados (Figura $2 \mathrm{f} \mathrm{y}$ g). Por otro, se registró el uso de elementos modelados en el cuello y cuerpo de la pieza para lograr elementos o 'rasgos' de representaciones antropomorfas o zoomorfas (Figura 2c y d). En algunos casos también se adicionaron elementos al pastillaje.

Cada uno de los recursos técnicos aparece asociado a ciertos elementos plásticos en particular (Figura 3). Las técnicas de incisión y pintura fueron utilizadas principalmente para la confección de diseños geométricos. Los elementos realizados por incisión incluyen motivos de líneas paralelas, agrupaciones de círculos, hileras de puntos, líneas delimitando espacios rellenos de puntos y figuras geométricas rellenas por 'sombreado zonal'. Los elementos decorativos pintados incluyen líneas rectas, triángulos y círculos, además de algunos diseños más complejos compuestos por líneas escalonadas e hileras de puntos.

El pequeño tamaño de muchos de los fragmentos cerámicos analizados impidió en ocasiones reconocer las configuraciones mayores o combinaciones de elementos que constituyeron el diseño final logrado. En los casos que fue posible, se estudió la organización y disposición de los elementos plásticos en las vasijas diferenciando configuraciones (Jernigan 1986) tanto en la selección del espacio de la pieza sobre el cual se realizaron las representaciones (campo de representación), en la combinación de distintos elementos, como en el movimiento y arreglo espacial de los mismos (simetrías).

Existe cierta correspondencia entre la forma de la vasija y las expresiones que porta. Los espacios seleccionados para ejecutar las representaciones están bien establecidos para cada forma y aparecen configurados en ocho modalidades diferentes (Figura 3):

CR 1. Sobre el borde de piezas abiertas (decoración modelada).

CR 2. Superficie interior del cuerpo en piezas abiertas (decoración pintada).

CR 3. Desde el borde hasta el comienzo de la base en formas abiertas (decoración incisa o pintada).

CR 4. Sobre sector superior y borde en piezas abiertas (decoración modelada e incisa).

CR 5. Sobre el cuello de formas restringidas (decoración modelada, al pastillaje e incisa).

CR 6. Cuello y cuerpo de formas restringidas tipo jarra o jarro (decoración pintada o incisa).

CR 7. Extensión no determinada en el cuerpo de formas abiertas o cerradas (tanto para decoración incisa como pintada).

CR 8. Sobre el asa.

En los casos en que se pudo determinar la simetría, se observó la utilización de la traslación y en un caso se presentó la reflexión desplazada ${ }^{3}$. Cuando las expresiones

\footnotetext{
3 El análisis de simetría permitió observar la estructura del diseño en relación al movimiento de las unidades a lo largo o alrededor de un eje. La traslación consiste en el movimiento del elemento decorativo a lo largo de un eje, generalmente se presentó siguiendo un eje horizontal. La reflexión desplazada combina la traslación con la reflexión en espejo a través de la línea eje.
} 

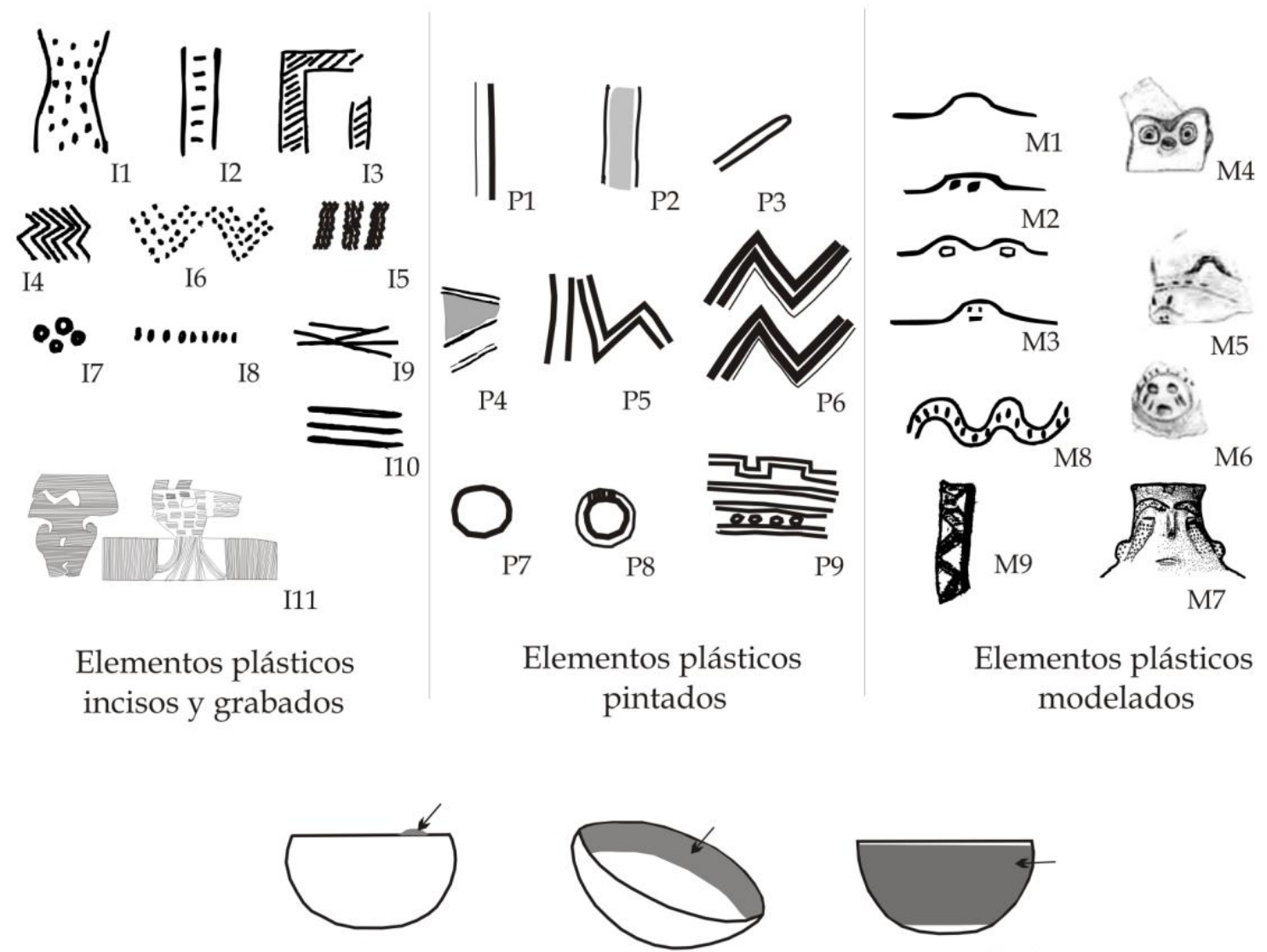

CR 1

CR 2

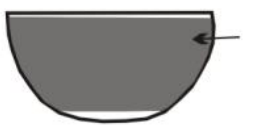

CR 3

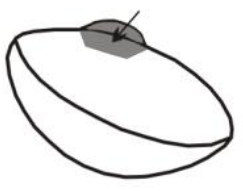

CR 4
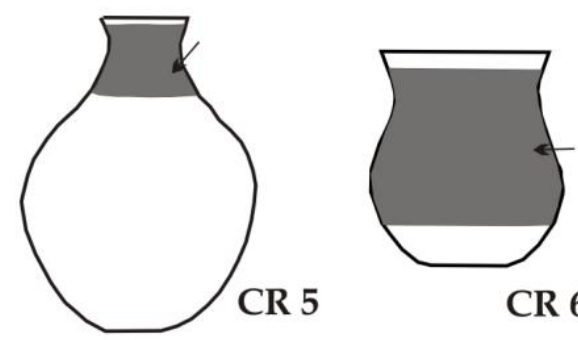

CR 6
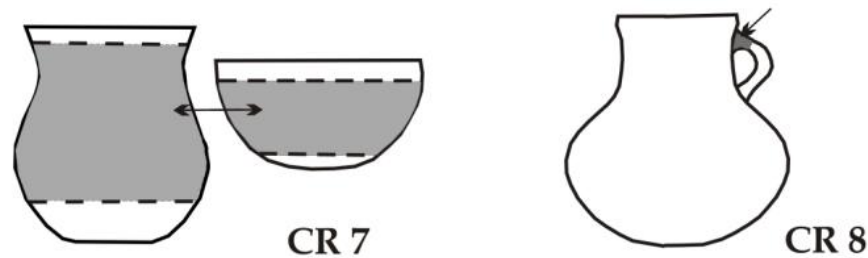

Campos de representación

Figura 3. Elementos plásticos y campos de representación en la cerámica de Yutopián.

son resultado de la utilización de elementos geométricos, las configuraciones resultantes plantean una lectura de espacio continuo (Quiroga 2001) alrededor de la pieza. Contrariamente en el caso de las vasijas efigie, logradas a través del modelado y del uso del cuerpo de la pieza como elemento de representación, la lectura es de tipo frontal o plana.

Del total de fragmentos recuperados en las excavaciones
( $n=12926$ fragmentos) un pequeño porcentaje fue diagnóstico para reconstruir el repertorio de formas que fue desplegado en Yutopián. La estimación del número mínimo de vasijas (NMV) ${ }^{4}$ en cada una de las

\footnotetext{
4 El número mínimo de vasijas (NMV) fue calculado asignando fragmentos a un mismo recipiente. Este cálculo se realizó teniendo en cuenta diámetros estimados a partir de los fragmentos de borde, tipo morfológico y grosor de los bordes, tratamiento de la superficie y características macroscópicas de la pasta.
} 
estructuras permitió considerar el equipo doméstico que circuló en diferentes habitaciones y evaluar el consumo de los distintos tipos de contenedores y los elementos iconográficos y compositivos presentes en estos espacios.

\section{Vasijas, diseños y recursos plásticos en los distintos espacios de las unidades domésticas}

La unidad doméstica denominada Núcleo 1 (Figura 4) está compuesta por tres estructuras semicirculares (Estructuras E1, E2, E3) construidas en piedra, algo hundidas por la excavación de la roca de base y adosadas a un gran espacio subcircular o patio (Patio N1).

En la E1, el cálculo del NMV dio como resultado 18 recipientes, de los cuales trece corresponden al grupo Fino/Intermedio y cinco al Ordinario. En este último grupo ninguna pieza presentó elementos de diseño y la terminación de superficie fue por alisado, excepto por un cántaro donde se utilizó el pulido (Tabla 2).
Las representaciones plásticas se concentran en el grupo Fino/Intermedio. Las tres piezas de este último grupo corresponden a formas restringidas y se encuentran cubiertas por un baño de color blanco. Una de ellas es una olla de cuello evertido, las otras dos, son cántaros de cuellos estrechos y cuerpos grandes globulares. Uno de ellos es de tipo efigie antropomorfo, con la representación de un rostro humano en el espacio del cuello (Figura 2d), mientras que la forma globular de la pieza insinúa el cuerpo del personaje representado. El rostro está conformado por tiras de arcilla incisas a modo de cejas, la nariz modelada y ojos representados por gruesas incisiones horizontales. Debajo de los ojos sobre las mejillas, aparecen múltiples líneas cortas verticales.

De las diez vasijas del grupo Fino siete muestran diferentes recursos plásticos. Cinco cuencos hemisféricos presentaron incisiones y aditamentos de pasta en el borde logrando pequeños modelados semicirculares o cabecitas
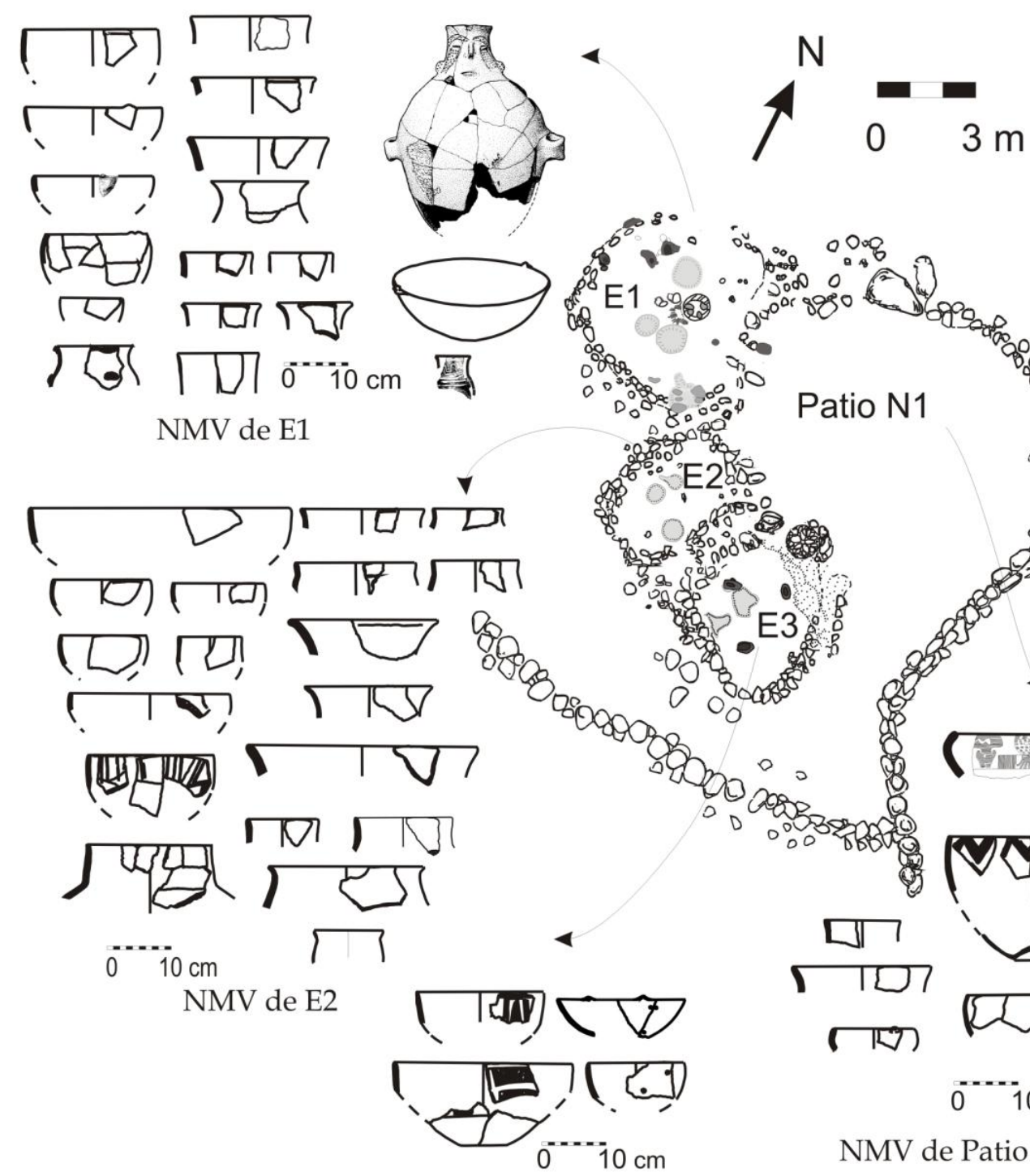

Vasijas abiertas de E3

Figura 4. Núcleo 1. Vasijas, formas y elementos plásticos en las diferentes estructuras. 


\begin{tabular}{ccccccc}
\hline \multirow{2}{*}{$\begin{array}{c}\text { Unidad } \\
\text { doméstica }\end{array}$} & \multirow{2}{*}{ Estructura } & $\begin{array}{c}\text { Con Rep. } \\
\text { Clásticas }\end{array}$ & $\begin{array}{c}\text { Sin Rep. } \\
\text { Plásticas }\end{array}$ & $\begin{array}{c}\text { Con Rep. } \\
\text { Plásticas }\end{array}$ & $\begin{array}{c}\text { Sin Rep. } \\
\text { Plásticas }\end{array}$ & NVM \\
\hline \multirow{2}{*}{ Núcleo 1 } & E1 & - & 5 & 8 & 5 & 18 \\
& E2 & - & 7 & 1 & 11 & 19 \\
& E3 & - & 1 & 4 & 2 & 7 \\
& Patio N1 & - & 2 & 3 & 1 & 6 \\
Núcleo 2 & E4 (oc. inf) & 1 & 6 & - & 1 & 8 \\
& E4 (oc. sup) & - & 3 & 3 & 2 & 8 \\
& Patio N2 & - & 5 & 1 & 5 & 11 \\
\hline
\end{tabular}

Tabla 2. Resumen del Número Mínimo de Vasijas (NMV) por estructura de los grupos Ordinario y Fino/intermedio, distinguiendo entre piezas con y sin representaciones plásticas.

zoomorfas (Figura 2f). Una jarra presenta líneas incisas cortas sobre el asa y una pequeña jarrita de sólo $7 \mathrm{~cm}$ de diámetro de boca y $10 \mathrm{~cm}$ de altura presentó un diseño de líneas escalonadas y rectas pintadas en blanco sobre fondo rojo comparable con los diseños de ejemplares del 'estilo Condorhuasi' (Figura 2a).

En la E2, donde se determinó un NMV igual a 19, siete vasijas son del grupo Ordinario, 12 corresponden al grupo Fino/Intermedio. En el primer grupo predominan las formas restringidas, las únicas dos piezas abiertas presentan un baño rojo en su superficie. Las piezas Intermedias corresponden todas a ollas. Mientras que entre las piezas del grupo Fino prevalecen las formas no restringidas. Sólo una pieza presenta representaciones de tipo geométrico, un cuenco hemisférico simple de pasta fina donde con pintura de color negro se practicaron líneas rectas y en zig-zag en el interior del recipiente.

La E3 presentó un NMV de siete, una olla de la serie Ordinaria y seis vasijas de la serie Fina/Intermedia. En este grupo existen un cántaro del tipo Intermedio y cinco contenedores de la serie Fina de los cuales cuatro presentan representaciones plásticas. Una jarra tiene un diseño inciso y en las piezas de tipo abierto se observaron diferentes recursos estilísticos: una escudilla gris pulido presenta pequeños modelados sobre el borde, en un cuenco se utilizó el 'sombreado zonal' conformando diseños geométricos y otro cuenco fue grabado con haces de líneas ejecutadas con un elemento de punta múltiple.

En la estructura Patio N1 se estimó un NMV igual a seis. Dos son de tipo Ordinario sin representaciones y cuatro corresponden al grupo Fino. En este último grupo, una escudilla presenta un pequeño modelado, otra escudilla gris fue grabada con diseños figurativos zoomorfos y un cuenco profundo (Figura 2b) presenta diseños geométricos (triángulos) pintados en rojo, blanco y negro ${ }^{5}$.

\footnotetext{
${ }^{5}$ Las características estilísticas de ambas piezas junto al hecho de que fueron halladas formando parte de un rasgo diferenciable en la estratigrafía de la estructura patio condujeron a interpretar este evento como 'intrusivo' a la ocupación principal aquí estudiada (Scattolin com. pers). Este rasgo estaba constituido por un conjunto de piedras ubicadas en forma circular en la zona central del recinto. Allí se abrió una cuadrícula y se obtuvieron algunos fragmentos de la cerámica
}

La segunda unidad doméstica estudiada -el Núcleo 2 (Figura 5)- es algo más pequeña y simple que la descripta anteriormente y está compuesta por una habitación semicircular que se conecta con un amplio patio (E4 y Patio N2).

La estratigrafía de la E4 permitió diferenciar dos ocupaciones superpuestas. Del equipo de vasijas de la ocupación inferior estimado en ocho recipientes, sólo una correspondió al grupo Fino y no presenta representaciones plásticas. El resto son del grupo Ordinario y una olla exhibe aplicada una tira al pastillaje con incisiones gruesas.

La ocupación superior de la E4 presentó tres piezas de la serie Ordinaria y cinco de la serie Fina/Intermedia. De estas últimas dos fueron cántaros del tipo Intermedio, uno de ellos con representaciones antropomorfas similares al descripto para E1 (Figura 2c). De las tres piezas del grupo fino dos presentaban representaciones: una jarra con diseños geométricos de puntos y líneas incisas (Figura 2e) y un cuenco gris pulido con un modelado con incisión en el borde.

En el Patio N2, fueron estimadas 11 vasijas de las cuales cinco corresponden a piezas del grupo Ordinario y seis al grupo Fino/Intermedio. Sólo una jarra muy pequeña de $4.5 \mathrm{~cm}$ de diámetro de boca y $7 \mathrm{~cm}$ de altura presenta diseños geométricos incisos, son líneas rectas verticales que delimitan líneas cortas horizontales paralelas.

\section{Circulación, despliegue de representaciones y contextos en los diferentes espacios de las unidades domésticas}

Las distintas estructuras analizadas muestran un repertorio surtido de categorías de recipientes, diseños y modos de representar. Analizando las categorías de vasijas y los recursos plásticos y compositivos puestos 'en acción' vemos que las terminaciones de superficie más cuidadas y los diseños y representaciones se concentraron en las series Fina e Intermedia, las cuales comprenden, desde el punto de vista de las formas, vasijas del tipo jarra, cántaros medianos, cuencos medianos a pequeños, todos estos recipientes usualmente relacionados con las actividades

grabada con motivos figurativos y del cuenco pintado. 
de presentación y servicio, y al mismo tiempo, de mayor circulación y exposición en actividades compartidas por un cierto número de personas.

Las representaciones plásticas suelen estar presentes en categorías de vasijas que circulan en contextos de alta visibilidad y exposición pública (De Boer y Moore 1982). Por sus características de forma, menores dimensiones y paredes más delgadas tanto los cuencos, las escudillas, como las jarras y los cántaros son recipientes de alta transportabilidad, útiles para la contención y circulación de productos que deben ser servidos.

Las expresiones plásticas se concentraron en los contenedores asociados al servicio, aquellos usados para el consumo de alimentos, líquidos u otros productos. Es posible que al ser objetos cerámicos transportables y de mayor exposición hayan sido los elegidos para portar representaciones siendo éstas expresión de aspectos sociales, referencias identitarias o de otro tipo.

Puede observarse que, por ejemplo, las vasijas del tipo Intermedio, posiblemente utilizadas en el transporte y servicio de líquidos, presentaron expresiones plásticas específicas. Son los cántaros efigie antropomorfos donde se observa la selección metonímica de ciertos rasgos faciales que se repiten en los diferentes ejemplos y han sido ejecutados de manera similar en todos los casos, usando las técnicas de pastillaje, modelado e incisión. En estas vasijas existe un claro esquema de representación que se distingue no sólo por la selección de los elementos plásticos usados sino también por su disposición y la

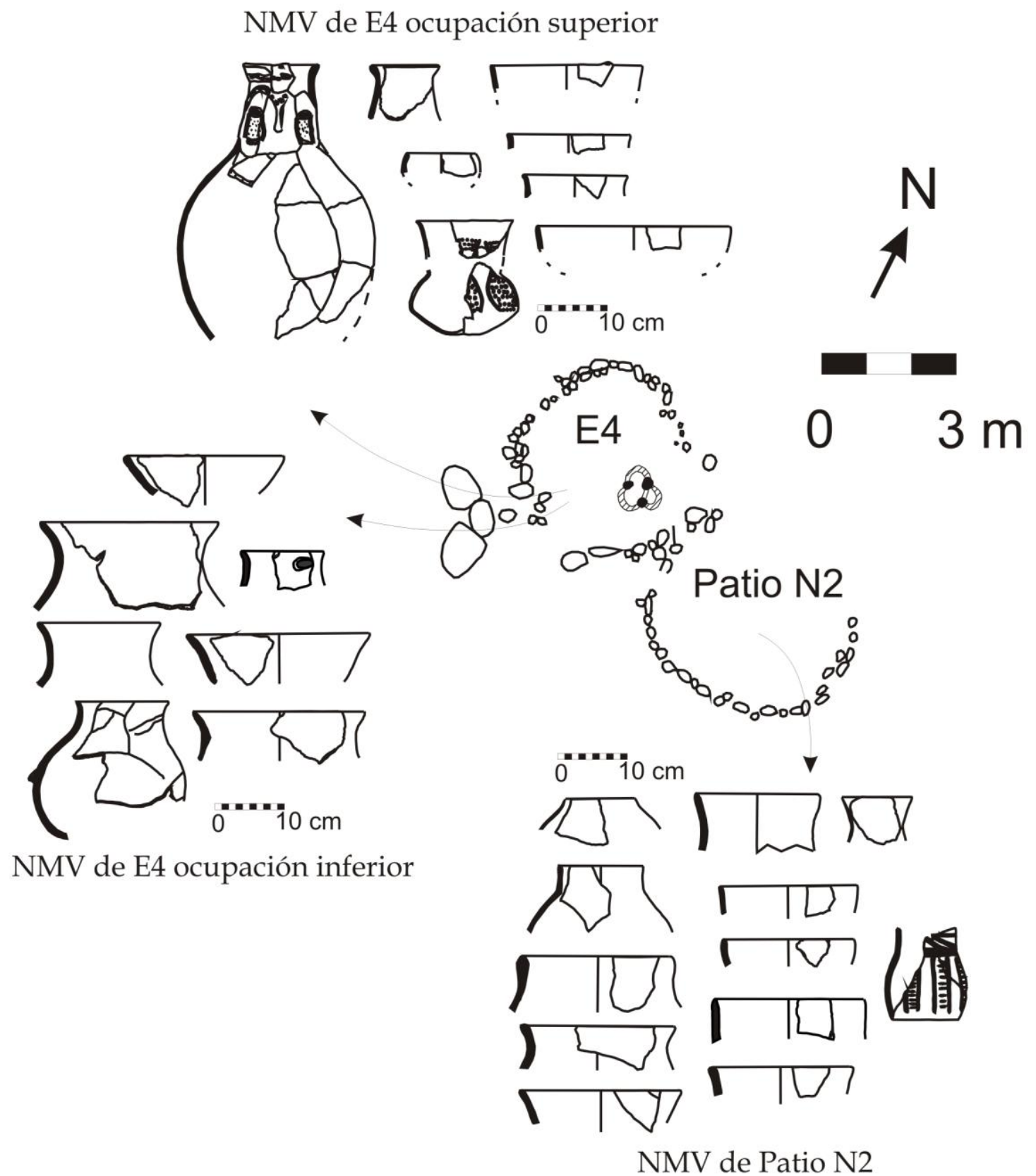

Figura 5. Núcleo 2. Vasijas, formas y elementos plásticos en las diferentes estructuras. 
integración de cada aditamento a la forma del cántaro. En la representación humana se priorizan algunos rasgos faciales: ojos, nariz, cejas al pastillaje mientras que el cuerpo del personaje esta constituido por el volumen mismo de la vasija.

Por su parte, en el conjunto Fino donde predominan los cuencos y jarras pequeñas se invirtieron una mayor diversidad de recursos plásticos incisos, modelados o pintados, marcándose una distinción con las vasijas del grupo Ordinario donde sólo un ejemplar presentó una tira al pastillaje con incisiones. Este conjunto Ordinario que es útil para la preparación y cocción de alimentos, pero pensado para una circulación restringida al ámbito de la cocina, un espacio más limitado y con exposición a agentes de desgaste como el fuego, no habría justificado una inversión de trabajo y habilidad en la expresión de representaciones ni de terminaciones cuidadas.

Si observamos los equipos de vasijas de cada estructura vemos que en los distintos espacios de las unidades domésticas fue consumido un corpus de diseños y recursos estilísticos que circularon diferencialmente. La variedad de formas y representaciones plásticas no se distribuye homogéneamente por los espacios construidos. En el Núcleo 1, la E1 presentó en el piso de ocupación un fogón bien constituido, conformado por un anillo de arcilla endurecida y quemada sobre el cual se ubicaron cuatro piedras firmemente adheridas como para servir de apoyo. Investigaciones previas han hallado en esta estructura evidencias de preparación y consumo de alimentos (Gero y Scattolin 2002). Campo (1997) menciona la existencia de restos de maíz en esta estructura, mientras que la presencia de elementos óseos diferencialmente representados indicarían tareas de reparto y distribución de carne de camélido (Izeta 2007). Estas evidencias son congruentes con la diversidad de recipientes que aparecen en esta estructura y que incluyen tanto vasijas Ordinarias con formas utilizables en la preparación y cocción de comidas y bebidas, como otros recipientes para el servicio de los mismos como son los cuencos grises pulidos o los cántaros globulares. También se halló la jarra pequeña pintada con diseños geométricos en blanco sobre rojo, muy elaborada, que no sería de servicio de alimentos sino que podría tener un carácter ritual o votivo. Además fueron encontrados otra serie de objetos como una pequeña figurita modelada en arcilla con forma de camélido, un vaso cilíndrico de piedra, un tortero de hilar y un instrumento de hueso, además de algunos desechos producto de la producción de metales (Gero y Scattolin 2002; Vandiver 1994) por lo que en esta habitación se habrían estado desarrollando múltiples actividades además de las claramente ligadas a la cocina.

La E2 ubicada al sur de la anterior presentó un conjunto de artefactos similar al de la E1. Aparecen las mismas categorías de forma pero con menor inversión en recursos plásticos. Se diferencia por la mayor abundancia de piezas restringidas grandes de la serie Ordinaria y menos recipientes referidos al servicio, lo que permite considerar que en esta habitación se podrían haber practicado actividades de almacenamiento.

La E3 presentó una variedad de vasijas pero se destacan las de servicio en las cuales se utilizó el sombreado zonal como recurso plástico para representaciones geométricas. En esta habitación la evidencia de artefactos líticos de molienda ha llevado a sugerir actividades de almacenaje y procesamiento de plantas en este recinto (Campo 1997) aunque la presencia de cuencos y jarras también nos estaría marcando el servicio de alimentos y líquidos.

Asociadas a estas tres estructuras, se halla el Patio del N1 de mayores dimensiones y que conecta a la E1 a través de un umbral de piedra. Este espacio ha sido interpretado como lugar de actividades compartidas (Gero y Scattolin 1999). Además de espacio para la ejecución de tareas productivas, podría haber sido un lugar de reunión no sólo para los miembros del grupo doméstico, sino también para otros miembros de la aldea en reuniones sociales y situaciones de comensalismo. El patio se destaca por contar solamente con cuencos y escudillas entre las vasijas del grupo Fino y por la menor cantidad de vasijas Ordinarias. Aquí actividades de mayor visibilidad y exposición colectiva, como reuniones con servicio de alimentos podrían haber facilitado un espacio para el despliegue de representaciones plásticas y recursos expresivos significativos.

Por su parte, el Núcleo 2 ofreció una configuración similar a la del conjunto anterior, aunque de menores dimensiones. En la ocupación superior identificada en la E4 se halló un fogón compuesto por tres arcos de arcilla elevada, divididos por tres piedras paradas y rodeado de un sedimento oscuro muy carbonizado. El estudio del registro óseo permitió identificar actividades de procesamiento de camélidos (Izeta 2007), mientras que la presencia de macrorestos vegetales carbonizados sugirió la preparación y cocción de alimentos (Campo 1997). En este contexto los recipientes cerámicos presentes corresponden en su mayoría a formas de servicio o almacenamiento temporario de líquidos (cántaros y jarras).

La ocupación inferior de la E4 presenta varios pozos cavados en la roca de base por debajo del nivel piso y se destaca por manifestar un equipo de vasijas muy diferente a los de las demás estructuras. Las vasijas Ordinarias fueron más abundantes que los recipientes de la serie Fina. En esta ocupación no aparecieron los cántaros de pastas Intermedias presentes en otros momentos de ocupación del sitio y la pieza del grupo Fino no está decorada. Asimismo se utilizaron recursos plásticos y formas no presentes en las otras estructuras. Por ejemplo, una jarra ordinaria presentó simetría dorsiventral en su silueta y una vasija del tipo Ordinario pero con un baño rojo muestra una aplicación al pastillaje alrededor de su cuerpo. En el Patio del N2, se hallaron piezas de pequeño 
tamaño y de morfología relacionada con el servicio.

En ambos núcleos el equipo doméstico se presenta conformado por categorías de forma y recursos plásticos similares pero diferencialmente representados. La distribución de los objetos y los recursos plásticos se asocia a actividades definidas y espacios particulares dando la idea que ambos núcleos habitacionales actuaron como unidades donde los agentes sociales consumieron ciertas formas y recursos expresivos en relación a las actividades practicadas.

\section{Consideraciones Finales}

Al analizar las representaciones plásticas y recursos aplicados en la cerámica, se observa un conjunto de recursos compartidos que circulaban entre los grupos domésticos de Yutopián. Es evidente que ciertas representaciones fueron elegidas para ser plasmadas en determinados objetos cerámicos y no en otros. Así se advierten los modelados en los cuencos, los diseños geométricos incisos o pintados de las jarras y las representaciones efigie antropomorfas en los cántaros.

Asimismo existen algunas vasijas cuyas combinaciones de forma, diseño y técnica remiten a 'estilos' que fueron definidos previamente para el período Formativo de otras áreas vecinas, por lo que algunas de estas maneras de hacer y representar circulaban por territorios extensos, desplegándose cualidades formales de los objetos compartidas por estas áreas y poniéndose en juego experiencias perceptuales semejantes.

La selección de determinados atributos y modos de representar nos habla de ciertos principios estéticos aplicados en la creación de los objetos, que hacen que esas expresiones sean apreciadas por quienes interactúan con ellas y desarrollan sus actividades en los espacios por donde circulan. Los agentes que consumen estas representaciones inscriben en los objetos sus apreciaciones, sus preferencias y todo un sistema de categorías y disposiciones que se ponen en juego en el campo social. Gombrich (2003 [1999]) plantea que para que ciertas imágenes sean seleccionadas y apreciadas debe existir un determinado 'entorno', o una serie de situaciones que favorezcan determinadas imágenes y determinados modos de representarlas. Este concepto es útil para pensar la interacción de agencias, donde intervienen la invención, la tradición, la citación de cualidades estéticas y las preferencias y disposiciones sociales de quienes consumen esas representaciones.

En Yutopián, podemos pensar en al menos dos 'entornos' o contextos sociales diferentes en relación al conjunto de representaciones observadas. Uno de ellos, representado por el nivel de ocupación inferior de la E4 que presenta escasez de imágenes en el equipo doméstico y donde la única pieza que está decorada corresponde al ámbito más íntimo y de menor visibilidad de la cocina. El otro, correspondiente al Núcleo 1 y el nivel de ocupación relativamente más reciente del Núcleo 2 , donde se aprecia un despliegue mayor de representaciones y de recursos que circularon en el ámbito de lo doméstico pero que, al mismo tiempo y por su distribución en diferentes espacios, puede considerarse que fueron compartidos, posiblemente, en el consumo cotidiano de la aldea, en reuniones familiares o en determinados eventos $y$ festividades.

Las representaciones en los objetos fueron compuestas a partir del uso de ciertas configuraciones estilísticas que pusieron en juego determinados órdenes y simetrías (repetición de elementos, traslación, reflexión desplazada). Para poder circular, esas expresiones debieron conllevar la puesta en acción de códigos de reconocimiento socialmente construidos (sensu Bryson 1991) o 'esquemas prácticos' (en términos de Bourdieu 1995 [1992]), lo cual nos lleva a proponer un uso social de las representaciones más allá de la aparente primera función de los objetos y que tiene que ver con la expresión de códigos sociales de reconocimiento, maneras de hacer consensuadas y compartidas y propiedades estéticas valoradas.

Entre los 'entornos' vemos diferencias en la manera en que los bienes y las representaciones son exhibidos y consumidos por los agentes, uno ligado a la más antigua ocupación del conjunto habitacional Núcleo 2 y otro posterior. Con esta diferenciación no estamos proponiendo necesariamente la presencia de dos etapas discretas de ocupación del sitio, por el contrario el poblado pudo ir creciendo y modificando su configuración conforme a la dinámica social y poblacional. Sin embargo se advierten maneras diferentes de consumo de imágenes y de modos de representarlas. Lo mismo que maneras y representaciones en diferentes espacios y contextos de uso. De esta forma, si los objetos pueden ser 'marcas' para clasificar categorías (Douglas e Isherwood 1990) la presencia de estas diferencias nos está hablando de cambios en las valoraciones y preferencias de los agentes quienes a través de sus acciones (entre ellas el consumo de imágenes y objetos) establecieron esos sistemas de clasificación y mantuvieron o modificaron sus disposiciones culturales. Asimismo, al definir o reconfirmar estas valoraciones comunes también se contribuye al mantenimiento de identidades colectivas (García Canclini 1997) por lo que podemos presumir que estas imágenes actuaron como un sistema de comunicación o expresión social.

Por último, si bien existen estas preferencias compartidas, no se puede desadvertir la desigual distribución de representaciones y modos estilísticos y la conspicua aparición de ciertos recursos en algunos de los espacios habitacionales analizados. Posiblemente este consumo diferencial estuvo ligado a diferentes tareas desarrolladas por los agentes en la vida cotidiana, pero también pudo 
responder a las posiciones de éstos en cada uno de los espacios o contextos, a la distinción entre agentes en determinadas ocasiones como al desigual acceso a determinados bienes por parte de los mismos; cuestiones que también se encuentran implicadas en la construcción de juicios y valoraciones estéticas.

Ciudad Autónoma de Buenos Aires, 15 de junio de 2010

\section{Agradecimientos}

A M.C. Scattolin y J. Gero directoras de los proyectos llevados a cabo en Yutopián por incorporarme al equipo de trabajo, permitirme estudiar la cerámica del sitio y hacerme conocer el valle del Cajón y su gente. A Cristina además, por su generosidad de siempre para compartir registros y bibliografía. A Leticia Cortés por colaborar en la traducción del resumen.

\section{Bibliografía}

Bourdieu, P. 1995 [1992]. Las reglas del arte. Génesis y estructura del campo literario. Anagrama, Barcelona.

Bryson, N. 1991. Visión y pintura. La lógica de la mirada. Alianza, Madrid.

Bugliani, M. F. 2008. Consumo y representación en el sur de los valles Calchaquíes (Noroeste argentino): Los conjuntos cerámicos de las aldeas del primer milenio A.D. B.A.R, International Series, S1774, John and Erica Hedges, Oxford.

Campo, R. 1997. "What's in kitchen? The early formative "kitchen", food production and women at Yutopian". Department of Antropology, University of South Carolina, United States of America. Pp. 122. MS.

DeBoer, W., J. Moore. 1982. The measurement and meaning of stylistic diversity. Ñawpa Pacha, 20: 147-162.

Delgado, L. 1988. Los componentes estéticos de la práctica social. Notas para el estudio del arte prehispánico. Boletín de Antropología Americana 18: 33-48.

Douglas, M., B. Isherwood. 1990. El mundo de los bienes. Hacia una antropología del consumo. Grijalbo, México D.F.

Dutton, D. 1998. Tribal art. M. Kelly (ed.), The encyclopedia of Aesthetics, Vol.4, Oxford University Press, New York. http://www.denisdutton.com/tribal_art.htm

García Canclini, N. 1997. Ideología, cultura y poder. Facultad de Filosofía y Letras Universidad de Buenos Aires, Buenos Aires.

Gell, A. 1998. Art and agency. An anthropological theory.
Clarendon Press, Oxford

Gero, J., M. C. Scattolin. 1994. Hacia la comprensión del desarrollo de la jerarquización: un estudio en el Valle del Cajón (Catamarca, Argentina). Actas y Memorias del XI Congreso Nacional de Arqueología Argentina, San Rafael, Mendoza (en prensa).

Gero, J., M. C. Scattolin. 1999. Household Chronology at Yutopian, Valle del Cajón, Northwest Argentina. Northeast Andean Archaeology and Ethohistory Conference, Amherst, Massachusetts, MS.

Gero, J., M. C. Scattolin. 2002. Beyond complementary and hierarchy: new definitions for archaeological gender relations. S. Nelson y M. Rosen-Ayalon (eds.), In Pursuit of Gender: Worldwide Archaeological Approaches, pp. 155-171, Altamira Press, Walnut Creek.

Gombrich, E. 2003 [1999]. Los usos de las imágenes. Estudios sobre la función social del arte y la comunicación visual, Fondo de Cultura Económica, México.

Gosden, C. 2001. Making Sense: archaeology and aesthetics. World Archaeology, 33(2): 163-167.

Izeta, A. 2007. Zooarqueología del Sur de los Valles Calchaquíes (Provincias de Catamarca y Tucumán, República Argentina): Análisis de Conjuntos Faunísticos del Primer Milenio A.D. B.A.R. International, Series S1612, John and Erica Hedges, Oxford.

Jernigan, E. 1986. Non-hierarchical approach to ceramic decoration analysis. American Antiquity, 51(1): 3-20.

Quiroga, L. 2001. A través del arte: Una perspectiva arqueológica de las relaciones coloniales en el Valle de Santa María (Provincia de Catamarca). J. Berenguer, L.E. Cornejo, F. Gallardo y C. Sinclaire (eds). Segundas Jornadas de Arte y Arqueología, pp. 272-300, Museo Chileno de Arte Precolombino, Santiago de Chile.

Scattolin, M.C. 1999. Análisis y clasificación de los materiales cerámicos de Yutopián (valle del Cajón), MS.

Scattolin, M.C. 2007. Santa María antes del año mil. Fechas y materiales para una historia cultural. V. Williams, B. Ventura, A. Callegari y H. Yacobaccio (eds.), Sociedades Precolombinas Surandinas: Temporalidad, Interacción y Dinámica Cultural del NOA en el Ámbito de los Andes Centro-Sur, pp. 203-219, Instituto de Arqueología, Facultad de Filosofía y Letras, Universidad de Buenos Aires, Buenos Aires.

Scattolin, M. C., J. Gero. 1999. Consideraciones sobre fechados radiocarbónicos de Yutopian, Catamarca, Argentina. Actas del XII Congreso Nacional de Arqueología Argentina, Tomo III: 352-357, La Plata. 
Shanks, M., C. Tilley. 1987. Re-Constructing Archaeology. Theory and Practice. Cambridge University Press, Cambridge.

Shelton, A. 1992. Predicates of aesthetic judgement: ontology and value in Huichol material representation. J. Coote y Shelton A. (eds), Anthropology art and aesthetics, pp. 209-244, Clarendon Press, Oxford.
Vandiver, P. 1994. Análisis técnico preliminar de escoria y otros materiales de un piso de vivienda en Yutopian, Argentina. Actas y Memorias del XI Congreso Nacional de Arqueología Argentina, San Rafael, Mendoza, (en prensa).

Welch, P., C. Scarry. 1995. Status-related variation in foodways in the Moundville chiefdom. American Antiquity, 60 (3): 397-419. 